\title{
Quality Improvement in Athletic Training Education on Female Athlete Triad
}

Kristen A. Paloncy-Patel, EdD, ATC*; Melissa R. Penkalski, DNP, APRN, CPNP-PC, AE-C†; Shannon M. Hauschildt, MA, PA-C†, Natalie B. Allen, MEd, RDN†

*North Central College, Naperville, IL; †Missouri State University, Spring Field, MO

\begin{abstract}
There are significant health risks associated with the female athlete triad (Triad), therefore early detection and prevention is key. Athletic trainers often serve as the frontline defense and can have a crucial role in identifying the Triad. Yet knowledge, confidence, and practice standards in the recognition, referral and treatment is lacking. The purpose of the following Quality Improvement document is to provide athletic trainers with a framework for improving Triadspecific knowledge, confidence, and practice standards. The 2014 Female Athletic Triad Coalition consensus statement provides an evidence-based risk stratification system for detection and referral of the Triad. The Coalition suggests including Triad-specific preparticipation examination (PPE) screening questions and utilization of the Female Athlete Triad Cumulative Risk Assessment on all clearance and return to play decisions for female athletes. Though there are efforts to educate athletic trainers about disordered eating in athletes, these efforts do not specifically include the Triad. Many female athletes are currently being cleared at their PPE without being adequately assessed for this syndrome or without appropriate referral for management and treatment. Therefore, it is important for ATs to improve their knowledge, confidence, and practice standards specific to the Triad.
\end{abstract}

\section{Key Phrases}

Injury risk reduction, preparticipation exams and screening, college and university patient population, female athlete triad

\section{Correspondence}

Dr. Kristen Paloncy-Patel, North Central College, 30 North Brainard, Stadium Room 308. Naperville, IL 60540.

E-mail: Kapaloncy@noctrl.edu

\section{Full Citation}

Paloncy-Patel K, Penkalski M, Hauschildt S, Allen N. Quality Improvement in Athletic Training Education on Female Athlete Triad. Clin Pract Athl Train. 2020;3(2):6-14. https://doi.org/10.31622/2020/0002.3.

Submitted: November 6, 2019 Accepted: June 8, 2020

\section{CURRENT MODEL}

$T_{\text {he }}$ he syndrome of female athlete triad (Triad) was defined in 1997 in an American College of Sports Medicine position statement. 'Modified from its original definition, the three components of the Triad now include low energy availability with or without disordered eating, menstrual dysfunction, and low bone mineral density. ${ }^{1,2}$ Previously, the prevalence of the Triad was thought to be $1-4 \%$ and impacting mostly endurance athletes. ${ }^{1,2}$ However the current definition is much more encompassing and emphasizes the fact that the components do not need to present simultaneously. Therefore, the prevalence of the Triad expected to be much higher and among a much larger population.1,2 Since the Triad was identified, recognition and prevention strategies have emphasized a collaborative effort among healthcare providers. ${ }^{2-4}$ Due to the nature of many traditional athletic training settings and the high level of interaction with athletes, certified athletic trainers (ATs) often act as the frontline defense and an integral part of the Multidisciplinary team in identifying athletes at risk for eating disorders. ${ }^{4}$

The current processes in place to educate entrylevel athletic trainers on the assessment, identification, and management of the Triad fall under competency PHP-43, PHP-46, and PHP-47 in the 5th edition of the competencies published by the Commission on Accreditation of Athletic Training Education (CAATE). ${ }^{5}$ The competencies are ${ }^{5}$ :

- PHP-43: describe the principles and methods of body composition assessment to assess a 
patient's health status and to monitor changes related to weight management, strength training, injury, disordered eating, menstrual status and/or bone density status.

- PHP-46: Identify and describe the signs, symptoms, physiological and psychological responses of patients with disordered eating or eating disorders.

- PHP-47: Describe the methods of appropriate management and referrals for patients with disordered eating or eating disorders in a manner consistent with current practice guidelines. (NATA, 2011 , p. 15).

A new edition of the competencies will be published in 2020 by the CAATE, however the new standards continue to not specifically mention the Triad.6 In 2008, the National Athletic Trainers' Association (NATA) published a position statement on preventing, detecting, and managing disordered eating in athletes. ${ }^{4}$ This statement emphasizes that a crucial action for the AT is to establish a screening approach for disordered eating that "recognizes signs and symptoms of the full spectrum of maladaptive eating and weight loss behaviors, as well as predisposing risk factors associated with their development" (p.81). ${ }^{4}$ This can be achieved through medical history questions on the PPE as well as standardized, self-reported screening questionanaires. ${ }^{4}$ These questionnaires are not without their flaws for the athletic population. Athletes can feel shame, guilt, and denial associated with eating disorders or could be worried that their athletic careers could be jeopardized if their coach found out about their eating disorder. Therefore, the accuracy of responses in a self-reported screening questionnaire may be poor.4,7-9 Numerous screening instruments have been designed specifically for the athletic population. However, the concern about these screening instruments is the lack of extensive testing for internal and criterion validity, response bias, and generalizability. ${ }^{4,10}$ Therefore, the combination of screening methods to include the PPE, standardized self-reported questionnaires, individual interviews, and direct observation of athletes is described to be best practices for identifying and preventing disordered eating. ${ }^{4}$

The dissemination of knowledge regarding the screening and treatment of the Triad is lacking. ${ }^{1}$, 12 In a recent investigation of collegiate athletic trainers' knowledge of the Triad, it was found that while about half of ATs have heard of the Triad, most could not accurately define the disorder. ${ }^{12}$ Further, most ATs are not engaging in appropriately targeted screening or treatment recommendations. ${ }^{12}$ It is possible that since CAATE competencies and the NATA position statement addresses disordered eating as a more general category and do not specifically address the Triad, the knowledge, identification, appropriate screening, and treatment of the Triad remain low ${ }^{12}$ and do not lend to early detection of this syndrome specifically. ${ }^{12}$ Specifically, only $38 \%$ of ATs are able to correctly identify the three components of the Triad. While about half of athletic trainers screen collegiate athletes for unspecific eating disorders, only $26 \%$ of ATs screen specifically for the Triad. ${ }^{11,12}$ Furthermore, only $18 \%$ of ATs felt comfortable treating the Triad. ${ }^{11}$ In 2014, a consensus statement was published which included the "Female Athlete Triad Cumulative Risk Assessment Score" focusing on the clinical management of athletes affected by the Triad. ${ }^{13}$ The publication also includes a screening tool to identify and assess at-risk athletes. These guidelines, which are uniquely specific to the Triad rather than other screening instruments identifying unspecific disordered eating, were not found in most athletic training literature or implemented into practice within the athletic training profession. 
In a review of the practice processes for athletic trainers at the target collegiate setting, we found no formal screening tool were used to evaluate for the Triad. For two years prior to the start of the current study, 18 stress fractures in female athletes were recorded out of 234 total female athletes' measures (rate of .077 per 100 athleteexposures (AEs)). For national comparison, data from a 10-year NCAA Injury Surveillance Program reported a total of 671 stress fractures over $1,1778,145 \mathrm{AEs}$ for an overall injury rate of 5.70 per 100,000 AEs. ${ }^{14}$ Within our practice review, athletes who suffered these injuries lost a total of 848 days of sport participation, averaging 56 days of lost time. Of the 18 female athletes with recorded stress fractures, 14 saw the team Registered Dietitian (RD). Two athletes quit their athletic participation and no longer received services so were excluded from the study and two other females were referred but never met with the RD. Of the 14 athletes seen by the team RD, $85 \%$ were identified as having low energy availability with or without disordered eating and other Triad components. At this time, we questioned if there may be an improved process to help ATs increase knowledge specific to the Triad and confidence in early recognition which would result in improved practice.

The purpose of this quality improvement study was to determine if there were significant gains in knowledge, recognition/referral confidence, and practice standards in the Triad through an educational in-service and introduction to PPE Triad-specific screening questions and the Female Athlete Triad Cumulative Risk Assessment in a four-year, Division I institution with 17 collegiate ATs.

\section{PDSA CYCLE}

\section{Plan}

We first began by researching the specific recommendations for screening female athletes for the Triad and the Female Athlete Triad Cumulative Risk Assessment. Recommendations are to screen female athletes focusing on full menstrual history, energy availability, disordered eating history, and reasons for hormonal therapy use. ${ }^{15}$ In this research phase, we found the Triad Coalition reported that early detection of athletes at risk for the Triad is crucial to prevention. While there are concerns of efficacy for many screening tools, the recommendation is that all female athletes undergo annual screening with the triadspecific self-report questionnaire. ${ }^{13}$ A list of recommended screening questions may be viewed in Table 1. The Triad Coalition further recommends that if the athlete has any risk for one Triad component as identified through the screening process, a more in-depth interview and evaluation should occur. In addition, evidence on risk factors for the Triad demonstrate that low bone mineral density and bone stress injuries is greater with cumulative risk factors for the Triad and therefore should be considered before making clearance or return to participation decisions. ${ }^{13,16,17}$ The Female Athlete Triad Cumulative Risk Assessment developed by the Triad Coalition provides an objective method of determining the athlete's risk for the Triad by using evidence-based factors and assigning a point value based on the magnitude of risk (low, medium, high) for assessment criteria and scores. ${ }^{13}$ This risk assessment tool was used with permission and may be viewed in Table 2. The Triad Coalition recommends utilization of the Female Athlete Triad Cumulative Risk Assessment for all participation and return to participation decisions for female athletes. ${ }^{13}$

Next, we had conversations with our Team Physician, Team RD, and the Head AT. We first spoke with the Team Physician to see if he would support the implementation of the Female Athlete Triad Cumulative Risk Assessment and screening 
Table 1: Triad Consensus Panel Screening Questions*

Have you ever had a menstrual period? How old were you when you had your first menstrual period?

When was your most recent menstrual period?

How many periods have you had in the past

12 months?

Are you presently taking any female hormones (oestrogen, progesterone, birth control pills)?

- Do you worry about your weight?

Are you trying to or has anyone recommended that you gain or lose weight?

Are you on a special diet or do you avoid certain types of foods or food groups?

Have you ever had an eating disorder?

Have you ever had a stress fracture?

Have you ever been told you have low bone density (osteopenia or osteoporosis)?

*The Triad Consensus Panel recommends asking these screening questions at the time of the sport pre-participation evaluation.

Reprinted with permission

questions into the preparticipation physical examinations for all female athletes. We explained that he would have a role in ordering the bone dual-energy X-ray absorptiometry (DEXA) scans on all athletes (part of the Female Athlete Triad Cumulative Risk Assessment) as well as reviewing all scores and screening question responses before giving final clearance in the preparticipation physical examinations. We discussed the risks and benefits of preforming bone DEXA scans on all athletes and ultimately decided, given the very low radiation used, it was important to include these scans so that we could follow the Female Athlete Triad Cumulative Risk Assessment protocol in its entirety. We also explained that we would involve the ATs by first educating them on the Triad through an in-service and then having them take a role in administering/reviewing screening questions and conducting aspects of the Female Athlete Triad Cumulative Risk Assessment. He reviewed the evidence and agreed to support this.
We spoke to the Team RD (who was also part of the interdisciplinary research team) about her role in implementing the Female Athlete Triad Cumulative Risk Assessment and screening questions in the preparticipation physical exam. Her role would be to educate athletes that scored a moderate or high risk in the assessment on the Triad and develop nutrition goals with the athlete through individual meetings. She agreed to take on this role. It is important to note that the RD for our institution is based on-campus and has a high amount of direct interaction weekly within the athletic training room. There is potential for pushback on requiring large commitments from interdisciplinary team members such as the RD at institutions if their services are structured differently.

Finally, we spoke with the Head AT about 1) implementing the Female Athlete Triad Cumulative Risk Assessment and screening questions into all pre-participation physical examinations for all female athletes at the college, and 2) meeting with and educating all collegiate ATs on the tools and process. We predicted that by meeting with and educating all collegiate ATs on the tools and processes, their knowledge of the Triad, confidence in recognition and when to refer, as well as practice standards involving the Triad would increase. We determined as a group that was best to plan for the implementation of these two goals prior to both pre-participation physicals and before fall practices began.

The last step we took in planning was to develop a knowledge, confidence, and practice standards assessment tool that we could deliver to the athletic trainers. The research team created a 22question survey assessment that measured all variables. The knowledge, confidence, and practice standards survey assessment were examined for face validity by a panel of experts $(n=5)$ who had experience in survey design. No changes were made to the survey instrument 


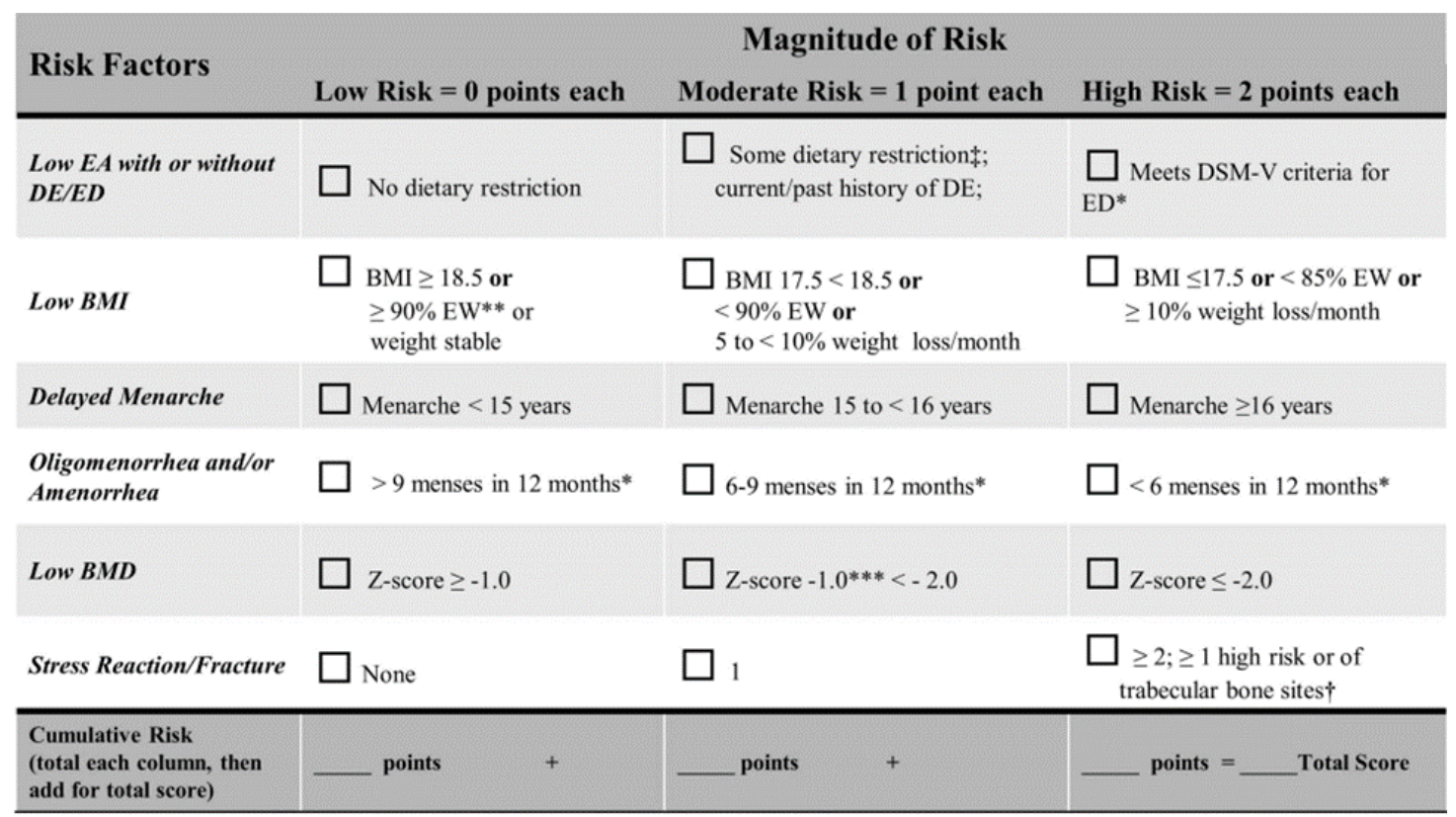

Table 1. Female Athlete Triad: Cumulative Risk Assessment

based on their feedback. Reliability of the survey instrument was determined by running a Cronbach alpha on a sample of athletic trainers $(n=17)$ to determine the internal consistency or average correlation of the items in the survey instrument. The overarching alpha for the whole instrument was calculated as a value of 0.92 which suggests the instrument has acceptable reliability.

\section{Do}

A pretest posttest design with the survey instrument was utilized to assess if knowledge, confidence, and practice standards in the Triad improved through the educational session and implementation of the PPE screening questions and Female Athlete Triad Cumulative Risk Assessment. On the day of the athletic training educational session, the survey instrument was administered to all 17 ATs ( 10 full time, 7 intern/graduate assistants) at the college. Responses served as the pretest assessment of Triad knowledge, confidence, and practice standards.

Following the pretest, in an educational session that lasted approximately one hour, the team RD presented information utilizing a self-developed

Copyright $(9)$ by Indiana State University All rights reserved. ISSN Online 2577-8188
PowerPoint Presentation on the Triad including components, effects of the syndrome, risks, signs and symptoms to watch for, and when to refer. In addition, information specifically on the universities' history with missed time for female athletes with previous Triad diagnoses and goals of the quality improvement study including the athletic trainers' role in the study was included. Finally, a review of the Triad-specific PPE screening questions and the components of the Female Athlete Triad Cumulative Risk Assessment tool was provided. It was explained to the ATs that they would have a role in assisting in the review of the PPE screening questions to identify areas of concern. It was also explained to the ATs that they also may have a role in assisting in administering the Female Athlete Triad Cumulative Risk Assessment. The research team decided it was best for the Team RD to lead this educational session because they were most familiar with the Triad and the Female Athlete Triad Cumulative Risk Assessment tool. Immediately after participating in the educational in-service, the survey instrument was again given to the athletic trainers which served as the posttest assessment of Triad knowledge, confidence, and practice standards. 
The educational in-service with the ATs was the quality improvement strategy that we focused on for this study as a way to improve ATs' Triadspecific knowledge, confidence, and practice standards as measured by the results of the pretest posttest survey. However, we would like to disclose that following this educational inservice, action did occur to further implement what was discussed. Like other years, ATs assisted in the preparticipation physical examinations of new and returning athletes on their assigned athletic teams which coincided with the start of specific athletic seasons. It was the ATs' role to review all screening questions (now including those specific to the Triad) in the medical history section of the PPE with the athletes on their team(s). Following this, several graduate assistant ATs completed the Female Athlete Triad Cumulative Risk Assessment on all female athletes in the universities' biomedical laboratory. When considering implementation of this process, please note DEXA scans must be completed by a trained administrator and it is not required that this person be an AT. DEXA scans were performed on all female athletes by the ATs under the order of the Team Physician. Lastly, after the review of all PPE screening questions and the generation of a score for the Female Athlete Triad Cumulative Risk Assessment, those who scored a moderate or high risk for the triad were identified and referred to the Team RD for follow up. We followed this detailed process annually over the next 3 full academic years and tracked new Triad referrals and diagnoses over this time period.

\section{Study}

Prior to computing analyses, the responses on the knowledge assessment was screened for accuracy, missing data, outliers and assumptions (normality). The knowledge assessment had 9 items on the pretest and posttest; however, a summary score for both tests were derived and these values were screened and included in the statistical analysis. Data appeared to be accurate without missing values. Also, there were no outliers assessed by boxplots in JASP. Lastly, the data did not appear to be normal as the distribution of the data showed a slight negative skew and had a significant value, using the $\mathrm{p}<.05$ criterion, for the Shapiro-Wilk Test of Normality $(p=.022)$. However, given that a Paired Samples t-Test is considered a robust analysis, especially with a large sample size, this was the test performed with a total sample size of 17.

A Paired Samples t-test was performed to examine differences in knowledge between the pretest and posttest. Results revealed a significant difference between these two measures, $t(16)=-8.90, p<.001, d=-2.16$. In other words, knowledge in the Triad significantly increased after participating in the education seminar (Pretest; $M=6.53, S=0.80$, Posttest; $M=8.47, S=0.62)$. See Figure 1 for a visual display of the means and +2 standard deviations.

Prior to computing analyses, the responses on the confidence and practice standards assessment was screened for accuracy, missing data, outliers and assumptions (normality). The confidence assessment had 6 items on the pretest and posttest while the practice standards assessment had 7 items; however, a summary score for both assessments for each test (i.e. pretest and posttest) were derived and these values were screened and included in the statistical analysis. Data appeared to be accurate without missing values or outliers assessed by boxplots in JASP. Lastly, the data appeared to be normally distributed as assessed by the distribution and the Shapiro-Wilk Test of Normality (confidence, $p=.859$; practice standards, $p=.193)$. There was a total sample size of 17 participants. 


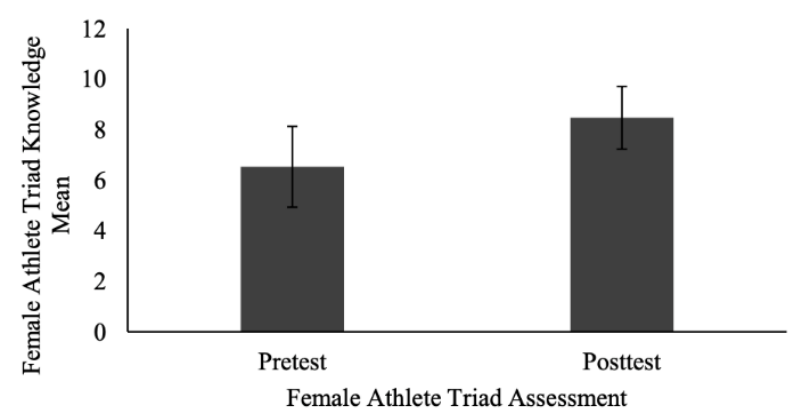

Figure 1. Athletic Trainers' Knowledge on the Female Athlete Triad Assessment

A Paired Samples t-Test was performed to examine differences in confidence between the pretest and posttest. Results revealed a significant difference between these two measures, $\mathrm{t}(16)=-3.46, \mathrm{p}=.003, \mathrm{~d}=-0.84$. In other words, confidence significantly increased after participating in the seminar (Pretest; $M=$ 35.24. $S=10.20$, Posttest; $M=40.82, S=9.22$ ).

A Paired Samples t-test was performed to examine differences in practice standards between the pretest and posttest. Results revealed a significant difference between these two measures, $t(16)=-4.24, p<.001, d=-1.03$. In other words, practice standards significantly increased after participating in the education seminar (Pretest; $M=4.06 . S=1.78$, Posttest; $M=5.12, S=1.32$ ).

The most significant barrier we found to implementing this educational session was finding a common time where the 17 ATs would all be together and fitting this into their already busy schedules. We determined it was best to provide the educational session separate from the annual in-service day. Due to this barrier it was determined that it should be explored if future educational sessions could be offered as an electronic training module to be completed independently.

\section{Act}

Based on what we learned from this quality improvement investigation study, short-term knowledge, confidence, and practice standards

Copyright (C) by Indiana State University All rights reserved. ISSN Online 2577-8188 in ATs' recognition and referral of the Triad can be significantly improved with a specific educational in-service including an introduction to utilizing Triad-specific screening question on the PPE and the Female Athlete Triad Cumulative Risk Assessment as a guideline for athletic clearance determinations.

Despite widespread awareness and efforts of the Triad, many female athletes are currently being cleared at their PPE without being adequately assessed for this syndrome or without appropriate referral for management and treatment. ${ }^{13,18}$ Even with structured education in athletic training education programs and the NATA Consensus Statement as a practice guide, there is a lack of standard of care guidelines for the evaluation and management of the Triad. ${ }^{13,18}$ Female athletes with the Triad have significant health risks therefore early detection and prevention is key. The 2014 Female Athlete Triad Coalition Consensus Statement on Treatment and Return to Play of the Female Athlete Triad Expert Panel provides an evidencebased approach to a developed risk stratification system that helps to increase the knowledge, confidence, and practice standards in detection and referral for the Triad. This quality improvement study provides evidence that when athletic trainers receive specific education on the Triad and utilize the PPE screening questions and Female Athlete Triad Cumulative Risk Assessment, their knowledge, confidence, and practice standards for the Triad significantly improves.

\section{ACKNOWLEDGEMENTS}

Thank you to Jessica Willis, RStats Coordinator at RStats Institute in Springfield, Missouri for assistance with statistical calculations.

\section{REFERENCES}

1. Otis $C$, Drinkwater $B$, Johnson $M$, Loucks A, Wilmore J. ACSM position statement: 
The female athlete triad. Med Sci Sports

Exerc. 1997;29(5):i-ix.

https://doi.org/10.1097/00005768$199705000-00037$.

2. Nattiv $A$, Loucks $A B$, Manore $M N$, et al. ACSM position statement: The female athlete triad. Med Sci Sports Exerc. 2007;39:1867-1882.

https://doi.org/10.1249/mss.0b013e3 $18149 \mathrm{f} 111$.

3. Temme KE, Hoch AZ. Recognition and rehabilitation of the female athlete triad/tetrad: a multidisciplinary approach. Curr Sports Med Rep. 2013 May 1 ; 12(3):190-9. https://doi.org/10.1249/JSR.0b013e3 $1829610 \mathrm{~b}$.

4. Bonci CM, Bonci LJ, Granger LR, Johnson $\mathrm{CL}$, Malina RM, Milne LW, Ryan RR, Vanderbunt EM. National Athletic Trainers' Association position statement: preventing, detecting, and managing disordered eating in athletes. $J$ Athl Train. 2008 Jan;43(1):80-108. https://doi.org/10.4085/1062-605043.1.80.

5. CAATE $20115^{\text {th }}$ Edition Competencies. Commission on Accreditation of Athletic Training Education Website. https://caate.net/wpcontent/uploads/2014/06/5th-EditionCompetencies.pdf. Accessed October 2019.

6. CAATE 2020 Standards for Accreditation of Professional Athletic Training Programs. Commission on Accreditation of Athletic Training Education Website. https://caate.net/new-standardsrelease-for-professional-masters-levelathletic-training-programs/. Accessed October 2019.

7. Wilmore JG. Eating disorders in athletes: A review of the literature. J Sci Sport Med. $2001 ; 4(2): 145-159$. https://doi.org/10.1016/s/14402440(01)80025-6.

8. Brownell KD, Rodin J. Eating, body, weight, and performance in athletes: Disorders of modern society.
Philadelphia, PA: Lea \& Febiger; 1992: 128-143.

https://doi.org/10.1016/S14402440.01.80025-6.

9. Johnson C, Powers PS, Dick R. Athletes and eating disorders: The national collegiate athletic association study. Int $J$ Eat Disord. 1999;26(2):179-188. https://doi.org/10.1002/(sici)1098108x.

10. Fairburn CG, Cooper Z. The eating disorder examination. British Journal of Sports Medicine. 2002;36(1):45-50. https://doi.org/10.1 192/bip.154.6.807

11. Troy K, Hoch AZ, Stavrakos JE. Awareness and comfort in treating the female athlete triad: are we failing our athletes? WMJ. 2006;105(7):21.

12. Kroshus E, DeFreeze JD, Kerr JY. Collegiate athletic trainers' knowledge of the female athlete triad and relative energy deficiency in sport. $J$ Athl Train. 2018;53(1): 51-59.

https://doi.org/10.4085/10626052.11 .29 .

13. De Souza MJ, Nattiv A, Joy E, Misra M, Williams NI, Mallinson RJ, Gibbs JC, Olmsted M, Goolsby M, Matheson G, Panel E. 2014 Female Athlete Triad Coalition Consensus Statement on treatment and return to play of the female athlete triad. Br J Sports Med. 2014;48(4):289. https://doi.org/10.1249/JSR.0000000 000000077.

14. Rizzone KH Ackerman KE, Roos KG, Dompier TP, Kerr ZY. The epidemiology of stress fractures in collegiate studentathletes, 2004-2005 through 20132014 academic years. J Athl Train. 2017;52(10): 966-975. https://doi.org/10.4085/1062-605052.8.01.

15. Tenforde AS, Barrack MT, Nattiv A, Fredericson $M$. Parallels with the female athlete triad in male athletes. Sports Medicine. 2016;46(2):171-82. https://doi.org/10/1007/s40279-015$\underline{0411-y .}$ 
16. Tenforde AS, Sayres LC, McCurdy ML, et al. Identifying sex-specific risk factors for stress fractures in adolescent runners. Med Sci Sports Exerc. 2013;45:184351.

https://doi.org/10.1177/0365354651 5572142.

17. Barrack MT, Gibbs JC, De Souza MJ, et al. Higher incidence of bone stress injury with increasing female athlete triad risk factors: a prospective multisite study of exercising girls and women. Am J Sports Med. 2014;42(2):949-958.

https://doi.org/10.1177/0363546513 520295.
18. Nattiv $A$, Loucks $A B$, Manore $M M$, et al. American College of Sports Medicine position stand. The female athlete triad. Med Sci Sports Exerc. 2007;39:186782.

https://doi.org/10.1249/mss.0b013e3 $18149 f 111$. 